\title{
School Building Defect Pattern
}

\author{
M. Mahli ${ }^{1}$, A.I Che-Ani ${ }^{2}$, H. Yahaya ${ }^{3}$, N.M. Tawil ${ }^{4}$, M.A. Othuman Mydin ${ }^{5}$ \\ ${ }^{1,2,4}$ Department of Architecure, Faculty of Engineering \& Built Environment,UniversitiKebangsaan \\ Malaysia (UKM), Bangi 43600, Malaysia \\ ${ }^{3}$ Faculty of Architecture and Built Environment, Twintech International University College of \\ Technology (TWINTECH), Kuala Lumpur 52200, Malaysia \\ ${ }^{5}$ School of Housing, Building and Planning, Universiti Sains Malaysia, 11800, Penang, Malaysia
}

\begin{abstract}
In providing a conducive learning environment for the student, the school building must be in good condition. This paper is evaluating the existing condition of primary school building in Sarawak, Malaysia. It focuses on building defects pattern for school building. The primary data collection is from the school building condition survey with involvement of 24 primary schools. The schools have been selected using simple random sampling and stratified sampling (of school age as the variable of selection). The reporting method is based on Condition Survey Protocol (CSP) 1 Matrix. Data analysis covers descriptive and inferential statistics. The analysis carried out found that the overall 4,725 defects have been identified. The building defect pattern is mainly on Ground Level of 3,176 defects, the highest number of defects components found on walls (798). 16.2\% defects are cracks from 11 common defects and most of all the highest score of defects based on age of the building were the building in the range of 11 to 20 years.
\end{abstract}

\section{Introduction}

The condition of school buildings is a very important factor in influencing the school environment and should be evaluated. However, there is lacked of published research in this field in Malaysia. The evaluation of school's building has not been formally developed. Since the school building is the main asset to the learning process, information on the current condition to the building is very important in the school's management. This study focuses on assessing the condition of school buildings, which one of the keys processes in the life cycle of a comprehensive asset management and facilities management. This assessment is important that the asset of the building is capable of supporting a school's core operations, which need to operate efficiently and effectively in providing a quality learning environment to the school users. This paper discusses the evaluation of school buildings condition based on CSP1 Matrix's assessment and analysis, focusing on building defects pattern for school building.

\section{Literature Review}

Maintenance of school building includes activities to maintain school facilities as to keep it in good condition. In Malaysia, school building maintenance usually neglected [1] and there are no 
sufficient guidelines for this process [2]. Maintenance work is not only necessary to the aging building. It is needed as to new building as well. New building will not remain constant during its lifetime [3]. Assessment of building condition is therefore needed as one of the proactive steps in managing and maintaining the performance of school facilities.

School is the building that used for the teaching purposes, and classrooms are physical spaces that designed to support in person teaching and learning activities. There is a significant impact of the school building conditions on student achievement $[4,5,6,7,8,9,10]$ because the built environment can influence users' behavior [11]. The relationship between schools building condition with student achievement was explained by Uline and Tschannen-Moran [9] who asserts that student from school with the better environment showed higher achievement. Schneider [12] added that school facilities had a direct impact on teaching and learning, while good school facilities can be provided by an efficient maintenance. Besides, characteristic of the occupied space affect the exchange of information and working environment. In addition, the physical condition of schools affects the behaviors and attitudes of both the teachers and students. The building and spaces reflect the message of life, activities and social values of users. The features such as color, shape and arrangement are able to help students and teachers to identify a clear mental image of the environment.

Extraction from a report issued by the MOE [13], typically operational and maintenance cost is between $60-80 \%$ of the total cost of facility during its lifetime and revealed that there were weaknesses into asset maintenance activities carried out by the government. This action will reduce the future maintenance cost, and it must be done by the experts.

\section{Materials and Methods}

Data for the evaluation of school building condition is gathered from samples of public school in Kuching, Sarawak. Data collection and analysis conducted based on CSP1 Matrix. There are 134 public primary schools in Kuching Division [14]. The sampling criteria used are based on school age, which refer to the first building constructed for the school which in the range of one year to 65 years. Two sampling methods used are simple random sampling and stratified sampling. Variable of Selection (VOS) used for the calculation of sample size was the rate of school age. The calculation of sample size was using the Simple Random Sampling (SRS) formula. Based on the calculation, 24 samples of school have been selected. The condition of building component is evaluated using CSP1 Matrix [15]. This protocol requires the information of every defect to be assessed in terms of its condition and priority. All defects identified are assessed and recorded on-site with the evidence (photos and plan tag). The score obtained from the scoring system determine the level of defects/component such as good, fair and dilapidated. Besides, the possible cause of the defects is also identified. This information is recorded in Defect Sheet, and then it was transferred to the Schedule of Building Condition [15]. A summary of finding such as the number of defects, total score and overall building rating are based on CSP1 Matrix. The data is statistically analyzed using the software of Statistical Package for Social Sciences (SPSS).

\section{Results and Discussions}

Assessment of the physical condition of school building at Kuching Division was conducted on 24 schools. In total, 4,275 defects were identified and the total mark is 45,868 . This means that the rating for overall condition of the buildings is 9.71 , which at a fair level but close to dilapidated.

\subsection{The Number of Defects Based on Building Levels}

According to Table I, the highest number of defects recorded on Ground Level of 3176 defects, while the lowest number recorded on Roof Level of 38 defects. Total defects recorded to show that the 
higher the level of building, the number of defects was decreasing. From the aspect of schools' age, the highest number of defects recorded by the school over 20 years old of 2838 defects. Highest defects on Ground Floor recorded by the school over 20 years old. However, for the other levels, the highest number of defects recorded by the schools between the ages of 11 to 20 years.

Table 1: The number of building defects based on schools' age and building levels

\begin{tabular}{llcccccc}
\hline Schools' Age & No. of schools & \multicolumn{7}{c}{ The number of defects } \\
\cline { 3 - 8 } & & Ground level & Level 1 & Level 2 & Level 3 & Roof Level & Total \\
\hline$<10$ & 2 & 100 & 94 & 95 & 0 & 0 & 289 \\
$11-20$ & 5 & 798 & 430 & 288 & 58 & 24 & 1598 \\
$>20$ & 17 & 2278 & 381 & 138 & 27 & 14 & 2838 \\
\hline Total & 24 & 3176 & 905 & 521 & 85 & 38 & 4725 \\
\hline
\end{tabular}

\subsection{The number of defects based on component}

There were 67 major component included in this survey. Table III presents the only component that has more than 100 defects. The highest number of defects found on walls (798) followed by floors (690), doors (629), fittings (575), windows (541) and ceilings (476). This component is the main parts to the building and its cover most of the buildings. Meanwhile, there are some other components (which are not listed in diagram 1) that have a little number of defects such as fire extinguishers, balcony railing and cabinets.

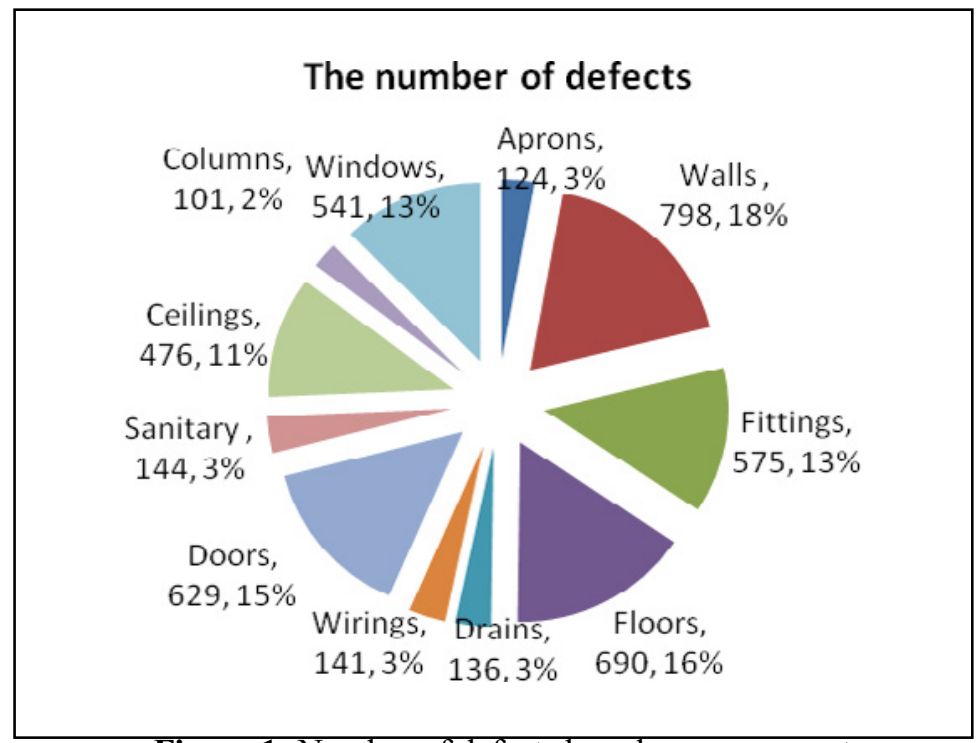

Figure 1: Number of defects based on components

\subsection{The Types of Defects}

There are 207 types of defects recorded during this survey. Table II shows the only types of defects that have more than 100 defects, which can be assumed to be common building defects. Based on Table II, there are eleven common defects with cracks as the highest types of defects $(16.2 \%)$ followed by missing $(13.9 \%)$, damaged $(8.6 \%)$, broken $(7.0 \%)$ and punch $(4.6 \%)$. Large number of cracks is because it often occurs on the walls and floor, which are major components of a building. 
Table 2: The Types of Defects

\begin{tabular}{lll}
\hline Types of defects & $\begin{array}{l}\text { The number of } \\
\text { defects }\end{array}$ & Percentage (\%) \\
\hline Punch & 230 & 4.6 \\
Missing & 683 & 13.9 \\
Rust & 177 & 3.6 \\
Water spot mark & 101 & 2.0 \\
Dirty & 108 & 2.2 \\
Broken & 346 & 7.0 \\
Decayed & 192 & 3.9 \\
Crack & 798 & 16.2 \\
Damaged & 422 & 8.6 \\
Malfunction & 114 & 2.3 \\
Water spot & 129 & 2.6 \\
\hline
\end{tabular}

*This table presents the only types of defects that has more than 100 defects

\subsection{The Relationship between Components with Sub-Components and Types of Defects}

Independent Chi-Square Test has been used to measure the correlation of relationship between the components and sub-components. Components is intended consists of doors, floors, walls, windows, ceilings, sanitary facilities, equipment, waste pipes and others. Sub-components consists of frames, ceiling boards, tiles, and so on. Based on Table 5, the results of analysis show that the components and sub-components have significant relationships. In addition, the types of defects are also connected to the components. This is proven after the Chi-Square Test conducted in which a p-value less than 0.05. In other words, in the event of defects in components such as doors, indirectly sub-components such as door leaf and frames also had an impact. In the same time, components also influence the occurrence of defects.

Table 3: Chi Square Test for sub-components and type of defects

\begin{tabular}{ll}
\hline Variables & $\mathrm{p}$-value \\
\hline Sub-component & $0.000^{*}$ \\
Type of defects & $0.000^{*}$ \\
\hline
\end{tabular}

\section{Conclusions}

As overall school building condition, it is in fair condition, but it close to dilapidated. The age of the schools is giving the idea of its building condition, where the older the school, the higher number of building defects is expected. Apart from this, the critical age of building condition is within the range of 11 to be 20 years old, where the number of building defects keeps on increasing. This is supported by the findings that the two schools which is found in dilapidated condition are the school that is more than 20 years.

This finding gives an implication for this study is going to help the school management to better plan and prioritize the school maintenance activity. By using CSP1 Matrix, it helps to prioritize the building defects. Defects with the red-coded means serious action need to be taken care first, and followed by the yellow-coded. This is also helping the maintenance budget to be spent wisely according to the priority. 


\section{Acknowledgment}

The authors would like to express their heartiest thanks to Ministry of Education, Malaysia, The National University of Malaysia, Twintech International University College of Technology and University Science Malaysia for supporting this research.

\section{References}

1. Syamilah Yacob. 2005. Maintenance management system through strategic planning for public school in Malaysia. Sarjana Sains (Pengurusan Pembinaan). UniversitiTeknologi Malaysia.

2. Nik Elyna Myeda, Syahrul Nizam Kamaruzzaman \& Pitt, M. 2011.Measuring the performance of office buildings maintenance management in Malaysia. Journal of Facilities Management. 9(3):181-199.

3. Abdul Lateef, O. A., Mohd Faris Khamidi \& AraziIdrus. 2011. Appraisal of the building maintenance management practices of Malaysian universities. Journal of Building Appraisal. 6(3/4):261-275.

4. Mendell, M.J., Heath, G.A. 2003. Do Indoor Environments in Schools Influence Student Performance? A Review of the Literature. Indoor Health and Productivity Project (IHP). USA.

5. Bosch, S.J. 2004. Identifying relevant variables for understanding how school facilities affect educational outcomes. PhD Dissertation. Georgia Institute of Technology.

6. Tiburcio, T. \& Finch, E.F. 2004.The impact of an intelligent classroom on pupils' interactive behavior. Facilities. 23(5/6): 262-278.

7. Tanner, C.K. 2008.Effect of school design on students outcomes. Journal of Educational Administration. 47(3):381-399

8. Adeogun, A.A. \&Osifila, G.I. 2008.Relationship between educational resources and students' academic performance in Lagos state, Nigeria. International Journal of Educational Management. 5\&6:144-153.

9. Uline, C. \&Tschannen-Moran, M. 2008. The wall speak: the interplay of quality facilities, school climate, and student achievement. Journal of Education Administration. 46(1):56-73.

10. Fram, S.M. 2010. One built environment: an example for school administrators and planners. Journal of Educational Administration. Vol. 48. No. 4 pp 468-489.

11. Rapoport, A. 1982.The Meaning of the built environment: A nonverbal communication approach. Sage. Beverly Hill. USA.

12. Schneider, M. 2002. Do school facilities affect academic outcomes? National Clearinghouse for Educational Facilities. Washington D.C.

13. GAO. 2011. Opportunities to reduce potential duplication in government programs, save tax dollars, and enhance revenue. Report to Congressional Addressees. United States Government Accountability Office. Mac 2011.

14. MOE. 2010. Statistic and number of school. Website of Malaysian Ministry of Education. Access: 22 Aug 2010. Last update: 22 Aug 2010.

15. Che-Ani A.I., Tazilan A.S.M., Kosman K.A. 2011. The development of a condition survey protocol matrix. Structural 